\title{
Caracterização de Pacientes Internados em Clínica Médica Segundo o Grau de Dependência do Cuidado de Enfermagem
}

\author{
Moraes, Aluana; Barbosa, Halana Batista; Campos, Terezinha; Nicola, Anair Lazzari \\ Universidade Estadual do Oeste do Paraná — aluanamoraes@hotmail.com
}

\begin{abstract}
Introdução: o processo de transição demográfica, vivenciado no país, traz um aumento progressivo e acentuado de sua população idosa, e, este processo é responsável por mudanças socioculturais, bem como, no perfil de saúde. Desse modo, a hospitalização dessa população tem despertado a preocupação de gestores e profissionais de saúde, devido ao tempo de internação, aos possíveis riscos e complicações, aos custos e também a carga de trabalho da enfermagem que demanda essa assistência. Objetivo: Analisar as características dos pacientes em tratamento clínico em uma unidade de clínica médica de um hospital universitário no Paraná. Metodologia: Trata-se de uma pesquisa descritiva, retrospectiva e documental com abordagem quantitativa. para a coleta de dados foi utilizado os registros no prontuário eletrônico, no período correspondente a 01 de março a 31 de agosto de 2013. As variáveis avaliadas foram sexo, idade, tempo de permanência, nível de complexidade assistencial e o diagnóstico médico. para análise do nível de complexidade assistencial utilizou-se o Sistema de Classificação de Pacientes (SCP) proposto por Fugulin. Resultados: Foram avaliados 244 pacientes, sendo $58,2 \%$ do sexo masculino. Quanto à idade $6,2 \%$ eram menores de 18 anos, 54,9\% apresentavam idade entre 18 e 59 anos e 38,9\% apresentavam idade acima de 60 anos. em relação ao tempo de permanência predominaram os pacientes maiores de 60 anos, que permaneceram em média 16,65 dias internados. Quanto ao nível de complexidade assistencial, $45,3 \%$ dos pacientes necessitavam de cuidados semiintensivos. Nessa categoria os pacientes são graves e recuperáveis, sujeitos à instabilidade de funções vitais, requerendo assistência de enfermagem e médica permanente e especializada. com relação aos diagnósticos médicos, predominaram os relacionados a doenças respiratórias $(19,67 \%)$, doenças gastrointestinais $(15,98 \%)$ e doenças do sistema cardiovascular $(13,11 \%)$. Conclusão: Os resultados evidenciaram que a população idosa se apresenta como a segunda maior categoria internada e foram os pacientes que permaneceram internados por mais tempo. Os diagnósticos mais prevalentes foram os relacionados às doenças crônicas que mais acometem os idosos, apresentam fatores de risco comuns e demandam por assistência continuada dos serviços de saúde. no que tange ao nível de complexidade assistencial, predominaram os pacientes que necessitavam de cuidados semi-intensivos. Cabe ressaltar o propósito do SCP como um valioso indicador, pois gera informação sobre as condições clínicas do paciente auxiliando no planejamento da assistência de enfermagem é um instrumento que subsidia a melhoria da qualidade assistencial ofertada, pois se mostra capaz de prever as necessidades de cuidado individualizado do paciente, facilitando o gerenciamento do cuidado e garante assim a segurança na assistência prestada.
\end{abstract}

Moraes, Aluana; Barbosa, Halana Batista; Campos, Terezinha; Nicola, Anair Lazzari. Caracterização de Pacientes Internados em Clínica Médica Segundo o Grau de Dependência do Cuidado de Enfermagem. In: Anais do Congresso Internacional de Humanidades \& Humanização em Saúde [= Blucher Medical Proceedings, num.2, vol.1]. São Paulo: Editora Blucher, 2014. ISSN 2357-7282

DOI 10.5151/medpro-cihhs-10816 